
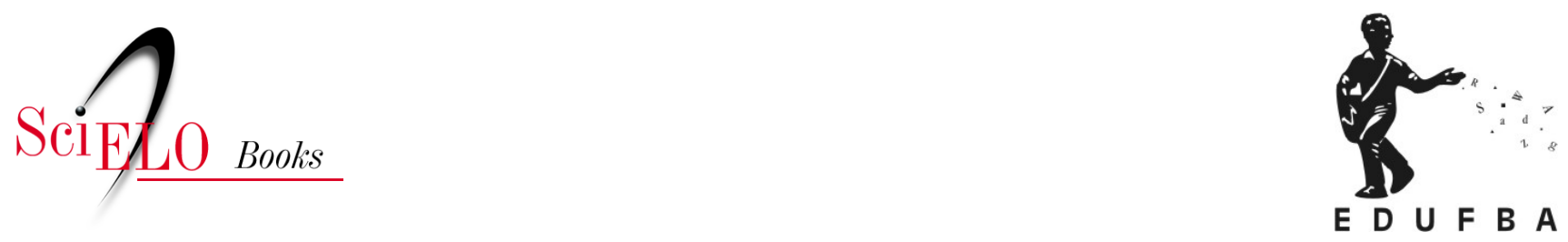

\title{
A realidade na luz da cena romântica
}

\author{
Eduardo Tudella
}

\section{SciELO Books / SciELO Livros / SciELO Libros}

TUDELLA, E. A realidade na luz da cena romântica. In: A luz na gênese do espetáculo [online].

Salvador: EDUFBA, 2017, pp. 353-371. ISBN: 978-85-232-1858-4.

https://doi.org/10.7476/9788523218584.0012.

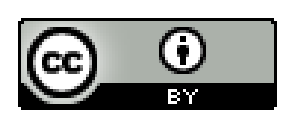

All the contents of this work, except where otherwise noted, is licensed under a Creative Commons Attribution 4.0 International license.

Todo o conteúdo deste trabalho, exceto quando houver ressalva, é publicado sob a licença Creative Commons Atribição 4.0.

Todo el contenido de esta obra, excepto donde se indique lo contrario, está bajo licencia de la licencia Creative Commons Reconocimento 4.0. 


\section{A REALIDADE NA LUZ DA CENA ROMÂNTICA}

As implicações visuais que apareceram na cena do século XIX ainda mostravam uma face poeticamente idealizada da arte, como se pode observar em $A$ arte poética [L'art poétique], de Boileau (1838, p. 28, tradução nossa): "Não há serpente ou monstro odioso | Que pela arte imitado não agrade aos olhos | De um pincel delicado a | habilidade graciosa | Do mais terrível objeto fará um objeto admirável". 64

Os versos de Boileau ganham força particular na metáfora que nomeia "pincel" o instrumento do artista, qualquer que seja a natureza do seu trabalho. É possível estender o alcance dessa imagem, apreendendo-a com flexibilidade: o poeta se refere tanto aos princípios da visualidade, aqui discutidos, quanto ao contexto integral de uma obra artística. Não somente o pintor, mas o escultor, o poeta, o ator, todo artista "empunha

64 "Il n'est point de serpent, ni de monstre odieux, | Qui, par l'art imité, ne puisse plaire aux yeux: | D’un pinceau délicat l'artifice agréable | Du plus affreux objet fait un objet aimable." 
um pincel". Na práxis cênica, por conseguinte, o palco/espaço que a abriga ganha a função de suporte e a obra é criada com um "pincel" que se constitui de instrumentos e materiais muito particulares, sendo a luz indispensável para a revelação da pintura, da imagem - ou agrupamento de imagens em movimento - que chamamos cena, espetáculo, teatro, performance art, acontecimento espetacular, entre outras denominações.

Em um momento no qual o espetáculo teatral se originava tradicionalmente no texto, o trabalho do dramaturgo é assim resumido por Diderot (1875, p. 363, tradução nossa): "Pintar de acordo com a paixão e o interesse, eis o seu talento". ${ }^{65}$ No contexto da presente abordagem a compreensão do "dramaturgo que pinta" é ampliada para incluir qualquer artista envolvido na elaboração da práxis cênica. Então, mais do que um texto contendo diálogos representados por caracteres impressos sobre uma página vê-se uma "espécie de pintura cênica", ou seja, a articulação de imagens que constituem a cena. Pode-se dizer, num certo sentido, que a luz também assume o lugar de "pincel”. E, para Diderot (1875, p. 374, tradução nossa), a qualidade dessas imagens deve apresentar um traço principal: "Se a natureza e a verdade forem uma vez introduzidas nos vossos palcos, na mais leve circunstância, logo se sentirá o ridículo e o desgosto em tudo que com elas contraste". ${ }^{66}$

Por natureza e verdade considere-se aqui uma representação figurativa da realidade, observando uma elaboração constituída de escolhas dos artistas, de artificialidades (positivas, artísticas, arbitrárias). Aquele que "pintava a cena", portanto, deveria atender a pressupostos muito particulares, aliando às imagens verdade e rigor:

Que vosso dramaturgo, tão logo julgue que vossa peça está digna de vos ser apresentada, traga o cenógrafo. Que ele a leia. Que o lugar da cena seja bem conhecido por ele, seja representado tal como é, e que ele entenda que a pintura teatral deve ser mais rigorosa e mais verdadeira que todos os outros gêneros de pintura. ${ }^{67}$ (DIDEROT, 1875, p. 374, grifo e tradução nossos)

Àquele tempo, essa pintura teatral não contava com a contribuição em separado de um responsável pelo pincel, ou seja, a luz. Essa incumbência poderia ser

\footnotetext{
65 "Peindre d'après la passion et l'intérêt, voilà son talent."

66 "Si la nature et la vérité s'introduisent une fois sur vos théâtres dans la circonstance la plus légère, bientôt vous sentirez le ridicule et le dégoût se répandre sur tout ce qui fera contraste avec elles."

67 "Que votre poëte, lorsque vous aurez jugé son ouvrage digne de vous être représenté, envoie chercher le décorateur. Qu'il lui lise son drame. Que le Heu de la scène, bien connu de celuici, il le rende tel qu'il est, et qu'il songe surtout que la peinture théâtrale doit être plus rigoureuse et plus vraie que tout autre genre de peinture."
} 
assumida pelo cenógrafo/pintor ou, quem sabe, pelo diretor. Consultando desenhos e pinturas que integravam os projetos ou foram executados por terceiros, para registrar imagens dos espetáculos, é possível imaginar o que era desejado por esses artistas.

Lendo a advertência de Diderot acerca dos cuidados com a indumentária encontra-se uma preocupação com a superficialidade usada para deslumbrar o público e alimentar a vaidade do ator, desconsiderando aquilo que o espetáculo pretenderia discutir ou provocar: "A pompa estraga tudo. [...] ela pode fascinar os olhos, mas não toca a alma" ${ }^{68}$ (DIDEROT, 1875, p. 375, tradução nossa) "Tocar a alma" parece querer indicar a necessidade de um figurino que seja parte determinante na caracterização "verdadeira" (ou real) da personagem, incluindo tal caracterização na unidade lógica do espetáculo: "Onde está a verossimilhança, se no momento de uma ação tumultuosa os homens têm tempo de se paramentar, como num dia de representação ou de festa?". 69 (DIDEROT, 1875, p. 375, tradução nossa)

Um ator que decide se paramentar num momento de crise pode impor desrespeito à lógica da ação (realista). É importante lembrar que mais tarde, em poéticas revolucionárias assentadas na negação de quaisquer recorrências à representação figurativa da realidade para efetivar sua revolução através da imagem criada na cena, o modo como o performer "se vestia" - ou ainda se veste - também recebeu, ou recebe, atenção especial.

Diderot solicitava uma imagem fundamentada na ação e, por conseguinte, no ambiente da peça, assim como nas nuanças de cada personagem, nas relações entre as personagens. Isso pode incluir a lógica do comportamento e a atmosfera pretendida, caracterizando a visualidade inerente ao espetáculo por ele projetado.

Diderot (1875, p. 376, grifo e tradução nossos) usa sua própria dramaturgia para exemplificar a expectativa de um autor:

Se o Pai de Família for encenado, eu creio que essa personagem [o pai] não poderá se vestir de maneira muito modesta. E não se pode negar a Cécile o traje de uma filha que vive com opulência. Eu concordarei se for dado ao Comendador um galão de ouro, uma bengala com bico de corvo. Se ele mudar de roupa entre o primeiro e o segundo ato, não me surpreenderá, pois se trata de um homem muito caprichoso. ${ }^{70}$

\footnotetext{
68 "Le faste gâte tout [...] elle peut éblouir l'oeil, mais non toucher l'âme".

69 "Quelle vraisemblance, qu'au moment d'une action tumultueuse, des hommes aient eu le temps de se parer comme dans un jour de représentation ou de fête?"

70 "S'il venait jamais en fantaisie d'essayer le Père de Famille au théâtre, je crois que ce personnage ne pourrait être vêtu trop simplement. II ne faudrait à Cécile que le déshabillé d'une fille opulente. J'accorderais, si l'on veut,
} 
Exigindo precisão no figurino para garantir a caracterização da personagem, Diderot (1875) sublinhou a verossimilhança instalada na sua obra. Isso pode ter produzido argumento para os comentários que o atrelam exclusivamente à mencionada representação figurativa da realidade. O estudo da visualidade da cena, no entanto, prefere buscar a compreensão da conjuntura de cada convenção e identificar os problemas que ela apresenta ao designer.

A verossimilhança da imagem já estava intimamente ligada à cena concebida por Diderot, assim como por outros artistas e estudiosos do século XVIII, mesmo antes do positivismo relacionado a Auguste Comte (1798-1857), apontado por muitos como aspecto substancial do pensamento que provoca e apoia o realismo. Ainda assim, não se pode negar o fortalecimento da busca pela representação da realidade na cena do século XIX, momento no qual a história localiza o aparecimento do movimento realista no teatro. Os passos iniciais da abordagem realista devem ser acentuados, mesmo que se leve conta as diferentes compreensões de "ilusionismo" na cena, assim como dos muitos "realismos" desenvolvidos a partir do século XX.

A defesa do tratamento realista não caracteriza, num certo sentido, exclusividade do pensamento teatral do século XIX uma vez que diversificadas manifestações teatrais foram ligadas a certo grau de realismo ao longo da sua confirmação como tendência da cena. Mesmo o melodrama que aplicava inúmeros efeitos especiais e culminava em um final feliz ocasionado pelas instâncias metafísicas que o permeavam poderia ser incluído no universo do realismo, já que também tratava do cotidiano de pessoas comuns.

O drama histórico em verso, ainda que não incluísse a ação e/ou o diálogo realista no modo como se veria mais tarde, pode ser ligado à proposição realista ao incorporar cenários e figurinos que buscavam acuidade histórica.

Desse modo, é possível compreender o espanto do público diante da "naturalidade" do desempenho virtuoso de David Garrick (1717-1779), cuja interpretação hoje poderia ser reconhecida como um passo na criação da fé cênica, que mais tarde derivaria da obra de Constantin Stanislavski (1863-1938). E mesmo se for tomado como exemplo o melodrama de Pixérécourt, ${ }^{71}$ cuja descrição apresentada por Bergman o relaciona à estética romântica que incorpora um mundo fantás-

au Commandeur, un galon d'or uni, avec la canne à bec de corbin. S'il changeait d'habit, entre le premier acte et le second, je n'en serais pas fort étonné de la part d'un homme aussi capricieux."

71 René Charles Guilbert de Pixérécourt (1773-1844), dramaturgo francês, reconhecido como expoente do melodrama moderno, e apontado como precursor na função de diretor teatral, quando, montando suas peças no Théâtre de la Gaités, em Paris, cuidava de diversos aspectos do espetáculo, observando a justeza dos figurinos, cenários e a representação dos atores, para o atendimento daquilo que, em sua opinião, era o melhor caminho para a peça. 
tico, repleto de cavernas, ruínas, castelos, eremitérios, em diversificados lugares e períodos históricos, podemos encontrar traços que apontam para a abordagem realista. Em O Peregrino branco ou Os órfãos da aldeia [Le pèlerin blanc ou Les orphelins du hameau (1801)], na rubrica que segue a apresentação das personagens, o leitor encontra a seguinte indicação: "A ação acontece na aldeia de Olival, em Provence, ano de 1645". 72 (PIXÉRÉCOURT, 1841, p. 82, tradução nossa)

Adiante, na primeira rubrica, do primeiro ato, encontra-se: "O palco representa o interior da aldeia de Olival; à direita, encontra-se a casa de Gervais; defronte dessa, a casa de Marceline. São seis horas da manhã, no verão". ${ }^{73}$ (PIXÉRÉCOURT, 1841, p. 83) Mesmo em uma cena povoada de luz (cores) e trevas, caracterizando o discurso visual romântico e incluindo espaços fantásticos, é possível identificar alusão explícita à realidade: fica indicada uma luz especificamente ligada ao ambiente no qual a cena se passa, apontando para um tratamento mais tarde vinculado à vertente científica, proposta pelo realismo do século XIX.

Como se pode notar, há compromissos com um tempo e um lugar objetivamente definidos. Diante da reduzida informação acerca da luz teatral incorporada ao melodrama, as ilustrações disponíveis podem dar pistas da grandiosidade pretendida pela abordagem romântica da natureza. Observando as imagens mentais criadas por Pixérécourt pode-se imaginar aquilo que o teatro buscava fisicalizar àquele momento, sugerindo, inclusive, a aplicação de cor na luz para criar atmosferas. Além disso, a cenografia tridimensional já figurava no interesse de artistas como Joseph-François-Louis Grobert, ${ }^{74}$ que questionou a exclusiva aplicação de tapadeiras laterais móveis pintadas para sugerir profundidade no palco.

A conjuntura técnico-artística que sustentava o teatro do romantismo já incluía importantes aspectos da aplicação da luz à cena, como a necessidade de criar incisivos contrastes de luz e sombra, assim como atmosferas suavemente implantadas em ambientes convincentes. Isso levou cenógrafos e técnicos a desenvolverem um intrincado controle mecânico para os instrumentos e acessórios, produzindo ilusão através de movimento, cor e transparência. Tal sistema, em grande parte protegido do olhar do espectador - e isso é muito importante para que se compreenda a busca pela ilusão realista - preenchia a cena de magia, tornando a luz elemento decisivo naquela estética.

\footnotetext{
72 "La scène est au hameau d'Olival, em Provence, l'an 1645."

73 "Le théâtre represente l'interieur du hameau d'Olival; à droite est la Maison de Gervais; vis-à-vis est celle de Marceline. Il est six heures du matin en été."

74 Autor do livro Da execução dramática... (De l'exécution dramatique...) publicado em Paris, em 1809.
} 
Diversificados elementos de suporte para instrumentos de iluminação cênica podiam ser encontrados, tais como a ribalta, as varas acima do palco, suportes móveis implantados diretamente nos dispositivos cenográficos, torres laterais dispostas entre as pernas, difusores, refletores, véus e telas de tafetá colorido que poderiam filtrar um ou mais instrumentos, provavelmente lamparinas a óleo. A combinação de tais elementos podia produzir variadas composições ou imagens - projetadas para cada momento, configurando a busca pela ilusão romântica de realidade. Da luz dependia substancialmente a efetivação dessas imagens.

\section{A LUZ QUE TOCA O ESPETÁCULO}

Ao tratar da luz no romantismo, Gösta M. Bergman faz uma incursão na documentação do Real Teatro de Estocolmo, na década de 1820, para exemplificar o conjunto de aparatos para iluminação aplicado com o objetivo de alcançar propósitos estéticos do teatro romântico. Ele comenta anotações acerca da representação de Gustaf Lagerbjelke (1777-1837), para o melodrama em versos Odin em Svithjod [Oden i Svithjod], ${ }^{75}$ música de J. F. Berwald e G. A. Brakel, em 1826, cujo tema é retirado da mitologia sueca e integra a literatura romântica do início do século XIX. Bergman (1977) cita a cenografia e as combinações de luz que aparecem nas anotações da montagem dirigida por Lagerbjelke, nas quais se pode apreender o interesse do diretor na luz do espetáculo. ${ }^{76}$ Além daquilo que está implicitamente indicado na dramaturgia, encontram-se nessas anotações aspectos importantes da contribuição da luz, incluindo cor, ritmo visual, intensidade e ângulos, dentre outros.

Juntando-se a isso os diários técnicos do teatro podem-se imaginar os movimentos de Odin. No início do primeiro ato, ao som do trovão, ele entra e ocupa o centro de uma organização simétrica de pedras nas quais os deuses estão sentados, próximos às tendas da tripulação que com ele viajou para tomar posse de Svithjod. Detalhes como filtros azuis, telas transparentes, varas de luz, nuvens que acompanham o trovão e os relâmpagos, além de observações sobre intensidade e tempo configuram indícios de um "roteiro de operação"77 para a luz do espetáculo. Um sistema de luzes que iluminava telões recortados era disposto em um dos

\footnotetext{
75 Odin é o herói e Svithjod, o antigo nome da Suécia, ou mais especificamente de um antigo território hoje denominado Svealand.

76 Essas anotações incluíam detalhes dirigidos ao professor $\mathrm{Hjelm}$ que, ao que parece, tinha particular responsabilidade nas questões referentes à luz e, na compreensão de Bergman, tinha a última palavra em muitos momentos.

77 Um documento do qual constam orientações para a operação do sistema de controle da luz usada no espetáculo.
} 
lados, o que já estabelecia decisiva assimetria com a luz. Tratava-se de um detalhe muito importante, pois é possível identificar a intenção de produzir uma qualidade "natural", através da desconstrução da simetria que imperava na convenção da luz para a cena naquele momento.

Um conjunto de nuvens era levantado em um tempo cronometrado de oito minutos, enquanto um grande véu azul era retirado através de um mecanismo elaborado para estabelecer movimentos sincronizados que representavam o nascer do dia e preparavam a atmosfera para Odin, que dizia: "Que a paz esteja com o povo, que a paz esteja com a nação". ${ }^{78}$ (LAGERBJELKE apud BERGMAN, 1977, p. 246, tradução nossa) Durante o desenvolvimento do primeiro ato, eram adicionados outros elementos do sistema de luz, como suportes atrás das pernas, determinando a visualidade que permaneceria durante todo o resto do ato e estabelecendo uma "estabilidade convencional" para a luz do dia. Depois que o sol se "erguia", a convenção definida para o espetáculo determinava, através da luminosidade instalada, que a ação ocorria durante o dia e dispensava outros movimentos da luz.

Segundo Bergman, o diretor fez um alerta importante sobre o nascer do sol chamando a atenção para que não fossem usados filtros vermelhos, uma vez que essa cor seria decisiva na elaboração das imagens para o quinto ato. Se a luz deveria ser fixa, "estática", no decorrer do ato em discussão, ela ganharia grande complexidade no próximo, cuja ação ocorria num salão do castelo de Gylfe em cujo centro ardia uma fogueira. Se isso, à primeira vista, não chamou a atenção do leitor, é importante que seja registrado: há uma fogueira no meio do espaço da cena!

O interior do castelo estendia-se até a profundidade da segunda perna ${ }^{79} \mathrm{e}$, ao fundo, através de uma porta, eram vistos galhos que pendiam, indicando as árvores, lá fora. Mais ao fundo, através do portão de um muro distante, contemplava-se uma paisagem marinha. A descrição do ambiente remete ao pensamento visual do teatro romântico, quando, na mesma imagem elementos arquitetônicos "se abrem" para visões da natureza, como se pode ver no esboço de Fabrizio Galliari para o cenário da ópera Enea nel lazio, música de Tommaso Traetta e libreto de V. A. Santi, cuja estreia se deu em Turim (1760). Fabrizzio e seu irmão Bernardino

\footnotetext{
78 "Peace to be As people, peace to be As land."

79 Denominação do elemento da configuração de um teatro italiano que tem as funções de definir os planos e proteger os bastidores do alcance visual do espectador. Geralmente confeccionado em tecido de cor preta, pode ser incorporado à cenografia, recebendo tratamento que o integre ao ambiente criado, e denominado tapadeira ou trainel.
} 
eram cenógrafos do Teatro Real de Turim, sendo mencionados nos documentos do período como os irmãos Galliari (Figura 94).

Mesmo sem acesso à documentação visual desses cenários pode-se presumir que os artistas levaram à tridimensionalidade do palco um aprendizado que se desenvolveu desde a Renascença, passou pelo Barroco e alcançou a abordagem romântica da pintura. Assim, eles puderam incorporar, ou reagiram às propostas de outros artistas, tais como a arquitetura de Canaletto (1697-1768), as atmosferas de Georges de la Tour (1593-1652), as personagens de Jacques-Louis David (1748-1825), todos os casos invadidos pela luz, assim como as paisagens luminosas de John Constable (1776-1837) e de Louis Jacques Mandé Daguerre (1787-1851) (Figuras 95 a 99).

Voltando a Odin em Svithjod. Bergman (1977, p. 248, tradução nossa) descreve o terceiro ato em um pequeno parágrafo sem registrar mudanças de luz em toda a sua extensão, e abre dizendo: "A luz do terceiro ato é desinteressante". ${ }^{80}$ O comentário final de Lagerbjelke, contudo, pode explicar a escolha por uma luz que, isoladamente, pode parecer "desinteressante". Considerando tratar-se de um momento no qual a indicação se refere a um ambiente sob a amplitude da luz do dia, vale a pena observar a solução técnica encontrada: "[...] há suportes padrão instalados em todas as pernas de madeira [que representam a floresta]". 81 (LAGERBJELKE apud BERGMAN, 1977, p. 248, tradução nossa)

É importante observar que, partindo de um segundo ato no qual o ambiente dado pela dramaturgia já indica imagens de significativa complexidade, pode ter sido intenção, ou intuição do autor, criar simplicidade visual no terceiro, com o intuito de estabelecer equilíbrio para a totalidade do espetáculo, através do contraste. Afinal, a ação ocorre numa floresta de pinheiros e bétulas, vendo-se ao fundo o Castelo de Gylfe, à luz do dia. Isso pode ter levado à decisão de elaborar uma atmosfera visualmente uniforme para o dia, justificada nas relações entre a ação e o ambiente. Assim, o diretor e seus associados não encontraram razão para propor movimentos na luz que poderiam, inclusive, parecer gratuitos, sem propósito, caracterizando mera imposição visual. Isso pode chamar a atenção do iluminador: mesmo em proposições atuais que defendem a chamada "dramaturgia da luz", é possível questionar o uso feérico de sucessivos efeitos de luz, apenas para afirmar sua "presença".

No quarto ato, a ação também se passa à luz do dia, mas o ambiente da cena apresenta uma composição diferente, provocando outro tratamento e interação

\footnotetext{
80 "The lighting in the third act is uninteresting."

81 "It is full day light: 'ordinary lamp bords on all the wood wings'."
} 
com a visualidade sem a necessidade de impor ou "inventar" efeitos. Baseando-se nos escritos de Lagerbjelke Bergman menciona uma parede que cruza a extensão do palco e tem como referência a quarta perna; atrás dela se vê o templo de Gylfes, situado em um bosque. No proscênio, um altar com noventa centímetros de altura. Suportes padronizados para a luz eram instalados atrás das pernas que incorporavam as árvores do bosque. Na frente da mencionada parede, havia um telão verde e, entre eles, luzes nas pernas; além disso, suportes adicionais estavam instalados no alto, provendo luz para o telão de fundo e, entre os telões duplos, luz, como a do sol. A mesma luz do dia que construiu a atmosfera do terceiro ato interagia agora com um novo ambiente, estabelecendo composições diferenciadas e sutileza na assertiva visual.

O quinto e último ato comprovava tal assertiva trazendo uma característica peculiar: a luz mantinha qualidade semelhante àquela do quarto ato durante quase toda a ação. Na parte final da peça, no entanto, a crise se precipitava e, numa reviravolta, o templo era incendiado e desabava, assim como a parede à sua frente. Vitorioso, Odin aproxima-se do altar, enquanto o crepúsculo avança. O diretor escreveu:

No início dessa [cena], os suportes de luz são gradualmente removidos das pernas, tanto no interior, quanto na parte interna da parede. Mas os suportes com lamparinas postos entre a parede e o telão devem permanecer até que o templo desabe; mas devem estar preparados para serem retirados imediatamente depois da queda. ${ }^{82}$ (LAGERBJELKE apud BERGMAN, 1977, p. 248, tradução nossa)

Havia um efeito especial para a queda do templo, assim como para o incêndio. Bergman completa informando que quando Odin chegava ao altar, o sol começava a se pôr e continuava imperceptivelmente o processo durante o longo monólogo. No momento que Odin fere a si mesmo com a própria espada, o sol já se pôs completamente, instalando-se a escuridão. Isso era alcançado posicionando-se filtros vermelhos instalados em tripés, em frente às luzes que iluminavam os telões. Além disso, uma vara era acionada atrás da boca de cena, com lamparinas nas quais se acrescentou o mesmo tipo de filtro que, vindo de baixo e de cima, preenchia a cena de vermelho. A ribalta era parcialmente retirada (baixada), e os filtros vermelhos eram adicionados a todo o sistema de luz que iluminava a cena.

82 "At the very beginning of this (scene) the lamp boards are gradually removed from all the wings, both inside and outside the wall. But the lamps standards between the wall and the backdrop mask are left until the the temple has collapsed; but are loosened to be removed immediately after the collapse." 
É possível, portanto, avaliar a imprescindível função que a luz cumpria no mencionado contexto, implantando as atmosferas da cena. (BERGMAN, 1977) Pode-se imaginar a quantidade de pessoas envolvidas no processo e o alto risco de incêndio para alcançar um resultado que hoje pode ser usado como um efeito banal, aplicando de alguns instrumentos e controle digital.

As sugestões e indicações encontradas na dramaturgia apontavam para a luz que o autor desejava vislumbrar na cena propriamente dita, instigando o diretor e seus colaboradores na tarefa de elaborar a visualidade do espetáculo. Ainda que algumas indicações pareçam demasiado simples, um artista criterioso encontraria ali significativa provocação para conceber um elaborado projeto de luz, como o que foi descrito acima, estabelecendo, portanto, uma relevante contribuição para a cena.

Em tal categoria de projeto, grande parte dos instrumentos propriamente ditos deveria permanecer fora do alcance visual dos espectadores, tornando a cena surpreendente e convincente naquele contexto estético-poético. A estratégia configurava-se como um importante estágio em direção ao realismo teatral, no qual o público teria acesso apenas aos resultados da luz projetada sobre a cena sem identificar a conjuntura tecnológica que produzia a ilusão.

\section{HENRY IRVING SOB A COR DA SOMBRA}

Na segunda metade do século XIX, um artista inglês introduziu contribuições importantes para a compreensão do espetáculo como um empreendimento visual. Rosenthal e Wertenbaker, já mencionados no presente trabalho, comentaram o trabalho do ator, diretor e produtor teatral Henry Irving (ou John Brodribb, 1838-1905). ${ }^{83}$ Segundo eles, a crítica da época mencionou o tratamento melodramático que as montagens de Irving impunham a qualquer que fosse o texto, em busca de intenso lirismo e do apelo de efeitos na cena. Os espetáculos ganhavam uma espécie de realismo impregnado de romantismo. Rosenthal e Wertenbaker descreveram a montagem de Macbeth:

A Lady Macbeth da montagem de Henry Irving tinha seu cabelo ruivo fumegante sob a luz de tochas, e Macbeth, na cena final, retirava uma tocha detrás de um pilar e atirava-a, em chamas,

\footnotetext{
83 Henry Irving administrou o Lyceum Theatre, em Londres, por 20 anos, desde 1878. Nesse período, ele combinava as funções administrativas com seu trabalho no palco; além de ator e diretor, supervisionava sistematicamente o tratamento visual dos seus espetáculos, discutindo com pintores, engenheiros responsáveis pelo sistema de gás, aderecistas e operadores de lâmpadas oxídricas (limelight). E, finalmente, com os engenheiros encarregados da luz elétrica, desde 1891, quando começou a experimentar essa tecnologia no teatro.
} 
no solo. Sir Herbert Beerbohm-Tree, como Nero, era transportado pelo palco em uma biga conduzida por cavalos treinados, e incendiava Roma, destruindo casas, atingindo templos e ateando fogo. Apresentando seu Macbeth, Beerbohm-Tree era acompanhado de um chocalhar de granizo e dos clarões ofuscantes de relâmpagos e, quando Macbeth aparecia na charneca, tendo atrás de si um fundo deslumbrante de céus tempestuosos, o público explodia em aplausos. ${ }^{84}$ (ROSENTHAL; WERTENBAKER, 1972, p. 53, tradução nossa)

Mesmo sem ter conhecimento do texto efetivamente usado no espetáculo comentado, é possível especular que a dramaturgia de Shakespeare servia como provocação, o que pode ter originado uma deliberada intervenção na obra. Irving propunha um tratamento particular da tragédia shakespeariana reinterpretando sua visualidade para atender aos traços estético-poéticos já citados. Ainda que processos dessa natureza nos quais a dramaturgia cede espaço para certa hegemonia da representação tenham acontecido antes, o exemplo de Irving demonstra que, assim como o dramaturgo, também o diretor confia na visualidade para criar sua poética, na qual a luz exerce papel decisivo.

O espetáculo de Irving parece ter desenvolvido um discurso visual muito próprio, como se pode apreender dos comentários do amigo e admirador, Bram [Abraham] Stoker (1847-1912), escritor, crítico de teatro e administrador financeiro da companhia de Henry Irving no Lyceum Theatre. Segundo Stoker, depois de assistir a um ensaio parcial de Fausto, em 1885, ele não acreditou no sucesso que todos previam para a montagem. Tratava-se de um espetáculo que envolvia grande elenco, muitos bailarinos e, no ensaio, a maioria deles já usava seus figurinos, criando uma cena com grupos visuais no palco, luz e ação, como descreve Stoker (1907, p. 94, tradução nossa): “[...] toda a correria, vertigem e cataclismo triunfante de uma possessão demoníaca irrestrita". ${ }^{85}$ O ensaio, no entanto, mostrava uma cena - em sua opinião - fria e irreal, o que o levou a procurar Irving no camarim ao final da sessão de trabalho para argumentar que aquele espetáculo não alcançaria

\footnotetext{
84 "Henry Irving had Lady Macbeth carried out with her red hair steaming in torchlight, and Macbeth, in the final scene, took a torch from behind a pillar and hurled it blazing to the ground. Sir Herbert Beerbohm-Tree as Nero was drawn across the stage in a chariot by live, stage-trained horses, and he burned Rome with crumpling houses, crashing temples and shooting flames. Introducing his Macbeth, Beerbohm-Tree had such a roar of wind, rattle of hail and blinding flashes of lightning that when Macbeth appeared on the heath against a dazzling background of stormy skies, the audience burst into applause."
}

85 "[...] and all the rush and whirl and triumphant cataclysm of unfettered demoniacal possession." 
o público no nível projetado pelo grande ator. Convencido da honestidade do seu julgamento, Stoker ouviu a resposta de Irving:

Isso é verdade; contudo, neste caso, não tenho dúvidas. Sei que a peça vai funcionar. Penso que você não foi capaz de julgar com precisão, no ensaio, hoje à noite. Você criou uma opinião, em grande parte, influenciada pelo efeito da cena do Brocken. Considerando esse ensaio, você tem razão; mas, você não viu minha indumentária. Eu não quero usá-la até que todo o resto esteja pronto. Então você verá. Vou manter cuidadosamente todo o projeto de cor relacionado com aquele cinza-esverdeado. Quando minha roupa escarlate flamejante aparecer junto com esse tom e, lembre-se que a cor será intensificada precisamente pela luz, que criará toda a imagem, de uma maneira que você nem pode sonhar. Na verdade, eu mesmo mal consigo perceber agora, embora saiba que vai funcionar. Você verá também como o vestido branco de Ellen Terry e, até mesmo aquela cicatriz vermelha em sua garganta, se destacará no meio daquele turbilhão de relâmpagos! [Figura 10o]. ${ }^{86}$ (IRVING apud STOKER, 1907, p. 94-95, tradução nossa)

Irving demonstrara sua capacidade de "pré-ver" as imagens visuais que constituiriam a cena, assim como sua confiança na luz e no poder do discurso poético-visual de promover a eficiência do espetáculo: "Ele viu na sua própria mente e com sua vasta e efetiva imaginação todas essas imagens e eventos, desde o início [antes que acontecessem]. ${ }^{87}$ (STOKER, 1907, p. 95, tradução nossa) Ficava clara a aplicação de um contraste cromático complementar sofisticado e simples, nas relações entre os cinzas frios esverdeados e o tom de púrpura provavelmente ligado à qualidade do alizarin-crimson. ${ }^{88}$

\footnotetext{
86 "That is all true; but in this case I have no doubt. I know the play will do. To-night I think you have not been able to judge accurately. You are forming an opinion largely from the effect of the Brocken. As far as to-night goes you are quite right; but you have not seen my dress. I do not want to wear it till. I get all the rest correct. Then you will see. I have studiously kept as yet all the colour scheme to that grey-green. When my dress of flaming scarlet appears amongst it and remember that the colour will be intensified by that very light it will bring the whole picture together in a way you cannot dream of. Indeed I can hardly realize it myself yet, though I know it will be right. You shall see too how Ellen Terry's white dress, and even that red scar across her throat, will stand out in the midst of that turmoil of lightning!"

87 "He had seen in his own inner mind and with his vast effective imagination all these pictures and these happenings from the very first."

88 Tons de vermelho que tendem a se aproximar do púrpura e a se afastar dos tons de laranja, no círculo cromático, alcançando densidade particular. Uma dessas cores, hoje colocadas à disposição pela indústria chama-se vermelho demônio. A alizarina é um corante e pigmento vermelho derivado originalmente da raiz da garança. $\mathrm{O}$ crimson, ou carmesim, é a cor do corante produzido por um inseto - kermes vermilio, um tom de vermelho forte, brilhante e pro-
} 
Em uma crítica publicada em 1887, antes do livro de Stoker, Joseph e Elizabeth R. Pennell já delineavam o contexto visual das montagens de Irving. Os autores comentavam a grande atenção dedicada às propriedades intelectuais da montagem e à dramaturgia propriamente dita, afinadas com a beleza da cenografia e a perfeição dos detalhes. Em uma breve assertiva, eles resumiram: "Você pode, sem dúvida, denominar a peça uma composição em vermelho, pois em todas as cenas a cor é concebida de modo que tudo se dirige para suas vestes de demônio". ${ }^{99}$ (PENNELL, J.; PENNELL, E., 1887, p. 310, tradução nossa) Observando os argumentos da crítica, outros aspectos importantes podem ser destacados, o que torna sua leitura integral de grande contribuição para pesquisadores interessados no discurso visual do espetáculo. Os autores comentaram a natureza das imagens criadas por Irving, destacando não apenas a beleza em si, mas sua contribuição para a harmonia da montagem, cumprindo o objetivo de fazer o espetador perceber, diante de si, a realidade das cenas e o tratamento da cor, ainda que ele mesmo sugira no simbolismo uma espécie de ameaça à tridimensionalidade do teatro, reduzindo-a ao que chamou de "pictorialismo" da cena. (ROUBINE, 1982b)

Considerando a fábula em questão, seu tema de origem religiosa, medieval, com alto grau de fantasia, o comentário citado abaixo apresentava uma reserva à caracterização desenvolvida por Irving para Mefistófeles, apontando um equívoco visual:

Fausto é uma lenda da Idade Média e como a personagem medieval foi preservada, não havia necessidade de exata datação. Os brocados e armaduras usados pelos cidadãos de Nuremberg [onde Irving decidiu localizar a ação], se não cópias das peças históricas, são sugeridos por imagens antigas. Mas, no caso do seu próprio figurino, o Sr. Irving conscientemente usou um casaco escarlate, uma grande pena de galo e a longa e afiada espada que Goethe tomou emprestada do Mefistófeles da peça de bonecos. O bigode pontudo e curto, assim como a barba de duas pontas do demônio criado pela ópera, não autorizados por Goethe, ele descartou, de modo imprudente, pensamos, pois ele parecia mais um Dante caído, como disse o Sr. Hatton, do que um Mefistófeles ridicularizador. Respeitando a roupa tradicional, mas desconsiderando o rosto tradicional, ele não nos

fundo; combinado com azul, resulta um certo grau de púrpura. Pode-se também encontrar essa denominação para descrever cores ligeiramente azul-avermelhadas que, em geral, estejam entre o vermelho e os róseos.

89 "You might, indeed, call the whole play an arrangement in red, for in all the scenes the color is toned so that it may lead up to his demon dress." 
deu nem o velho nem um novo Mefistófeles. ${ }^{90}$ (PENNELL, J.; PENNELL, E., 1887, p. 310, tradução nossa)

Em seguida, eles encontraram razões para qualificar positivamente o trabalho de Irving: "O principal mérito das imagens criadas pelo Sr. Irving não está nos materiais, disponíveis para todos os gestores [de companhias ou teatros], mas no uso artístico que ele faz. As mais belas cenas, de um ponto de vista pictórico são, naturalmente, as ruas, os jardins e o Brocken [uma montanha da Saxônia]". ${ }^{11}$ (PENNELL, J.; PENNELL, E., 1887, p. 309, tradução nossa) É verdade que eles parecem influenciados pela ilusão perspectivista, capaz de fazer o palco transformar-se em ambientes muito mais grandiosos do que parece possível. Por outro lado, a qualidade pictórica destacada levou os Pennell à observação de relações entre as cenas criadas por Irving e obras importantes da história da pintura. Tal observação sublinhava não somente a capacidade do diretor de ver na mente as imagens provocadas pela dramaturgia, mas, também, de fazer conexões com a visualidade presente na história das imagens, das artes visuais. Essas conexões fazem três referências à obra de Rembrandt (1634-1693), cuja influência pareceu decisiva para a visualidade do Fausto, de Goethe-Irving.

Segundo os autores, o local escolhido por Irving para o encontro de Margaret com Fausto, a Praça de São Lourenço em Nuremberg, tinha a precisa atmosfera para a ação cênica. Eles descrevem a vividez do ambiente e das personagens, destacando as meninas, que, usando vestidos escuros de lã, lembram aquelas que aparecem na pintura Cristo abençoando as crianças (1652-1653), que acreditavam da autoria de Rembrandt. ${ }^{92}$ A menção a outras obras, essas sim confirmadas como pintadas por Rembrandt sugere, na compreensão dos Pennell, a pesquisa efetivada na representação de Henry Irving, em busca de excelência visual:

90 As for time, Faust is a legend of the Middle Ages, and so long as the medieval character was preserved there was no necessity for exact dates. The brocades and armor worn by the citizens of Nuremberg, if not copied from, are suggested by, old pictures; but for his own dress Mr. Irving conscientiously wears the scarlet coat, the tall cock's feather, and the long, sharp sword which Goethe borrowed from the Mephistopheles of the puppet play. The pointed mustache and short, forked beard of the operatic demon, not being authorized by Goethe, he has discarded, unwisely we think, since he looks much more like a fallen Dante, as Mr. Hatton says, than like a mocking Mephistopheles. By respecting the traditional dress and disregarding the traditional face, he has given us neither the old Mephistopheles nor a new one.

91 The chief merit of Mr. Irving's pictures is not in his materials, those being at the disposal of all managers, but in the artistic way in which he uses them. The finest scenes from the pictorial standpoint are naturally the streets, the gardens, and the Brocken."

92 Durante algum tempo creditada a Rembrandt, e negociada em 1866 como obra sua, hoje os estudiosos concordam que o seu autor é o artista, também holandês, Nicholas Maes (1643-1693), que estudou pintura com Rembrandt, provavelmente entre 1648 e 1653 . 
A segunda cena de rua, o duelo [ou a morte de Valentines], que ocorre mais tarde na peça, no terceiro ato, é não menos realista e bonita. Quando a cortina sobe, ainda há uma cor suave no céu, ao final da longa e tortuosa rua, à esquerda, que rapidamente desvanece. A igreja é evidenciada, uma grande massa escura acima do palco, e se vê somente os pesados contrafortes e uma grande janela. O resto está na sombra, exceto em um canto onde há uma lamparina acesa diante de um santuário. Da escuridão e ao som de tambores distantes, os soldados retornam para casa depois das guerras - esposas, filhos e namoradas pendurados em seus braços, as alabardas coroadas com verdes, tochas e cressets levados bem no alto. Cada grupo era um estudo [visual] em si mesmo. Mas a melhor imagem veio depois que Mefistófeles cantou sua canção-demoníaca e atirou seu bandolim para longe, Valentine é ferido, e todo o povo da cidade corre pela longa rua e entra por todos os lados, Margaret e Martha saem da casa em frente à igreja. Na marcha dos soldados que retornavam havia a atmosfera de A Ronda noturna (1640-42) [Figura 101], de Rembrandt. Neste último grupo, o sentimento não é de uma única imagem, mas de todas as grandes imagens deste tipo, que já foram pintadas. O próprio Sr. Irving disse, que para sua composição tinha muitas delas, com frequência, em mente; e quando se analisa a imagem, considera-se que ela é magistral. O homem que carrega a tocha concentra toda sua luz no rosto de Valentine, a massa de rostos atrás dela espreita dentro uma misteriosa meia-luz, enquanto Margaret, com seu crime tipificado pela densa e negra sombra que cai sobre ela, encolhe-se no primeiro plano. [...] Essa cena lembra A Ressurreição de Lázaro, de Rembrandt [Figura 102], no seu arranjo de luz e sombra. Mas a imagem criada pelo Sr. Irving não é, de nenhum modo uma cópia: ao contrário, ela é o trabalho de um grande mestre da composição. ${ }^{93}$ (PENNELL, J.; PENNELL, E., 1887, p. 310, grifo e tradução nossos)

93 "The second street scene, which of Valentines death or duel, occurring much later in the play, in the third act, is no less realistic and beautiful. When the curtain goes up, there is still a faint color in the sky at the end of the long, twisting street to the left, but it quickly fades. The church rises, a great dark mass away above the stage, and you only see the heavy buttresses and one large window. The rest is in shadow, save in one corner where a lamp burns before a shrine. From out the gathering gloom and to the sound of distant drumming come the soldiers home from the wars, - wives, children, and sweethearts hanging to their arms, the halberds wreathed with green, and torches and cressets borne aloft. Each separate group is a study in itself. But the finest picture comes after Mephistopheles has sung his demon-song and flung away his mandolin, and Valentine is wounded, and all the towns - people hurry hack through the long street and from every side, and Margaret and Martha come out from the house opposite the church. In the soldiers marching home there was the feeling of Rembrandt's Night watch. In this last group the 
Tais comentários denotam a observação da cena como imagem (ou um conjunto de imagens em movimento), acentuando a contribuição do binômio luz-sombra para o teatro de Irving. Postos no contexto da segunda metade do século XIX, os relatos de Stoker indicam o trabalho de Irving como atitude que abria novos caminhos para a compreeensão da visualidade do espetáculo:

Com Irving tudo era diferente. Aquela marcha 'suave' dos soldados de Macbeth que retornavam fatigados após a batalha vitoriosa, vistos contra o sol que caía atrás da vasta charneca cravejada com manchas de luz brilhando sobre a água, a interminável fileira de soldados separados, um a um, individualmente, e em grupos de dois ou três, preenchia o palco para a celebração de uma infindável variedade, transmitindo uma ideia de força e poder que impressionou o espectador com uma sinceridade de valor inestimável. Irving sempre ajudava seu público a pensar. ${ }^{94}$ (STOKER, 1907, p. 15, tradução nossa)

Irving introduziu meios para controlar os conjuntos de bico de gás, elaborando combinações de cor e intensidade, baseando-se em efetiva experimentação. Ele pondera: "[...] a natureza raramente mostra grandes efeitos regulares de luz". (IRVING apud BERGMAN, 1977, p. 302, tradução nossa) Seu argumento refere-se às dinâmicas relações entre a luz natural e o ambiente, determinadas por diversos fatores, como a densidade atmosférica, além de outros obstáculos e/ou suportes. A interpretação cênica desses eventos sugere inúmeras composições de luz e sombra. Já aplicando a eletricidade ele elaborou diversificadas possibilidades de construção de imagens, pesquisando novos caminhos para a produção de cor e brilho na luz como a aplicação de lacas nas lentes das lâmpadas oxídricas [limelight] ${ }^{95}$ (Figura 103), e também nos próprios bulbos das lâmpadas elétricas.

\footnotetext{
feeling is not of a single picture, but of all the greatest pictures of this kind that have ever been painted. Mr. Irving himself has said that in its composition he had many of them constantly in his mind; and when you analyze his picture, you find that it is masterly. All the light from the torch held by the man who supports him is concentrated on the face of Valentine. The mass of faces behind peer out from a mysterious half-light, while Margaret her crime typified by the dense black shadow falling on her, cowers in the foreground. [...] One etching that suggests itself to us just now, Rembrandts Raising of Lazarus, is somewhat like this scene in the arrangement of light and shade. But Mr. Irving's picture is in no sense a copy: it is rather the work of a great master of composition."

94 “With Irving all was different. That 'easy' progress of Macbeth's soldiers returning tired after victorious battle, seen against the low dropping sun across the vast heather studded with patches of light glinting on water; the endless procession of soldiers straggling, singly, and by twos and threes, filling the stage to the conclusion of an endless array, conveyed an idea of force and power which impressed the spectator with an invaluable sincerity. In fact, Irving always helped his audience to think."

95 Luz oxídrica ou luz de Drummond [Thomas Drummond (1797-1840)] é um artefato aplicado à iluminação teatral, a partir da primeira metade do século XIX. Ele produz uma iluminação intensa, pela combinação de uma
} 
Bram Stoker destaca a atenção dedicada por Irving aos ensaios deluz, precedidos e/ou acompanhados de discussões sobre a natureza dos espetáculos, envolvendo cenógrafos e técnicos. Reconhecendo que sua função não o obrigava a frequentar ensaios, Stoker revela que os assistia frequentemente, pelo prazer de testemunhar aquele processo, presumindo que ali estavam sendo criadas novas abordagens do espetáculo teatral. Intuitivamente ou não, de acordo com Bram Stoker (1907), Irving trabalhou o potencial expressivo da sombra, até hoje pouco discutido e/ou aplicado ao teatro. A sombra é frequentemente associada ao "teatro de sombras", um gênero diferenciado que conta com sua própria abordagem teórica. Interessa aqui, a interação dinâmica entre a sombra e a luz, determinando que uma não seja percebida sem a presença da outra, isto é, mesmo que não esteja obviamente presente numa imagem, a sombra estará atuando. Ela exige, desse modo, muita atenção do artista pesquisador interessado na expressão visual do acontecimento espetacular, devendo ser tratada, artisticamente, como aspecto inalienável da imagem.

Irving e Stoker referem-se ao papel da sombra na constituição visual da imagem cênica em si. Deixar de pesquisar essa possibilidade, portanto, é abrir mão de um relevante elemento constitutivo da visualidade. Irving interessava-se por uma sombra que fosse capaz de tocar o público, construindo o que ele chamava de: "[...] verdadeiro realismo que todos deviam buscar". ${ }^{6}$ (IRVING apud BERGMAN, 1977, p. 259, tradução nossa)

Ao afirmar que Irving pintava as imagens no palco com várias combinações de luz (que, obviamente, inclui cor), Bergman toma emprestado de Stoker o verbo pintar. E Stoker até cita o próprio Irving quando esse sugere que pintor e ator devem se debruçar, um sobre a atividade do outro, já que, sendo os meios de produção das suas obras tão diferentes, esse estudo ampliará a capacidade artística de ambos. E justifica:

O pintor trabalha com materiais moldáveis, inanimados, não sensíveis, mas que se rendem ao mais suave toque. Sua criação é a incorporação do fantasma da sua imaginação, pois em arte o objetivo é glorificar e não meramente reproduzir. Ele usa formas e fatos da natureza que não pode desviar das suas leis. Mas os fatos naturais que ele assimila são reproduzidos no seu trabalho,

chama de oxi-hidrogénio dirigida contra um cilindro de cal viva (CaO/óxido de cálcio), que resiste a uma temperatura de $2.572{ }^{\circ} \mathrm{C}$, antes de entrar em fusão. A luz é produzida através da combinação de incandescência e candoluminescência (luz produzida pela excitação térmica dos íons, ou um átomo ou molécula, cujo número de eletrons é diferente daquele de prótons). Disponível em: <http://www.compulite.com/stagelight/html/history-4/ limelight-spot.html>. Acesso em: 16 maio 2009.

96 "[...] the true realism towards which all should aim." 
deificados pela força da sua própria imaginação. Os atores, por outro lado, devem trabalhar com materiais naturais e não plásticos, mas sensíveis e com algo da força e da fraqueza da carne e do sangue. $\mathrm{O}$ ator deve primeiro receber na própria mente através das palavras do dramaturgo a imagem fantasmal que ele reproduz o melhor que pode, com o material impreciso que a natureza lhe deu. ${ }^{97}$ (IRVING apud STOKER, 1907, p. 259, tradução nossa)

Parece claro que Irving se refere a um ator preocupado com as circunstâncias visuais do seu trabalho, interessado em criar imagens na sua própria imaginação e "pintá-las" na cena. E Irving estende essas relações com a visualidade ao trabalho do dramaturgo:

[...] o pintor e o poeta partem de diferentes pontos da gama de possibilidades naturais. O primeiro começa da natureza para alcançar a imaginação; o outro, da imaginação para chegar à realidade. E se os meios não forem inadequados e o esforço for honesto, ambos podem alcançar aquele verdadeiro solo no qual realidade e imaginação se unem..$^{98}$ (IRVING apud STOKER, 1907, p. 259, tradução nossa)

A interação poesia-visualidade (ou vice-versa) que mais tarde seria abordada por Italo Calvino (1998) para refletir sobre o papel da imagem no seu trabalho literário provocou em Irving uma imersão na pintura, na qual ele buscava provocação para as imagens nos seus espetáculos. Tal mergulho visual produziu aquilo que Bergman compreende como sua principal contribuição e que ainda hoje carece de discussão: "Mas Irving pintou o palco, não apenas com diferentes combinações de luz colorida, mas também com sombras [...]. E essa pode ter sido, na verdade, sua maior contribuição, antecipando o teatro moderno". ${ }^{99}$ (BERGMAN, 1977, p. 302, tradução nossa)

97 "Your painter works in moldable materials, inanimate, not sensitive but yielding to the lightest touch. His criation is the embodiment of the phantasm of his imagination, for in art the purpose is to glorify and not merely to reproduce. He uses forms and facts of nature that he may not err against nature's laws. But such natural facts as he assimilates are reproduced in his work, deified by the strength of his own imagination. Actors, on the other hand, have to work with materials which are all natural, and not all plastic, but are all sensitive with some of the strength and all the weakness of flesh and blood. The actor has first to receive in his own mind the phantasmal image which is conveyed to him by the words of the poet; and this he has to reproduce as well as he can with the faulty material which nature has given to him."

98 " [...] the painter and the poet begin from different ends of the gamut of natural possibilities the one starts from nature to reach imagination the other from imagination to reach at reality. And if the means be not inadequate, and if the effort be sincere, both can reach that veritable ground where reality and imagination join."

99 "But Irving painted the stage not only with different combinations of coloured light but also with shadows, [...]. And that may actually have been the greatest contribution, anticipating as he did, the whole modern theatre." 
Stoker já havia posto uma observação que caracterizava a compreensão de Irving, identificando o papel da sombra, na visualidade da cena: "De fato, descobriu-se que a escuridão, quando controlada, é um importante fator da luz [na cena]". ${ }^{100}$ (STOKER apud BERGMAN, 1977, p. 259, tradução nossa)

Intuitivamente, ou não, de acordo com as palavras de Stoker Henry Irving investigou a capacidade expressiva da sombra, até hoje pouco compreendida e pouco aplicada por artistas responsáveis pela visualidade do espetáculo (Figura 104). Quando se menciona a sombra no teatro é muito comum que se façam ligações com o mencionado teatro de sombras, outra vertente da questão, com espaço próprio de discussão.

É importante acrescentar que, quando se trata da sombra na cena, o termo realismo ganha contornos ainda por serem discutidos, incluindo as noções de verdade. Qualquer que seja a discussão da noção de verdade, em cena, ela somente será teatralizada, fisicalizada, com a aplicação de sombras (planejadas, calculadas), procedimentos que exigem mais do que o acaso ou sua combinação com ideias "geniais". Tais procedimentos integram o trabalho do theatre lighting designer, já comentado aqui, e que está por exigir um estudo aprofundado no Brasil.

Outro importante aspecto acentuado pelos Pennell revela um momento no qual Irving já investia na aplicação da luz elétrica e inclui a expectativa de uma representação de traços realistas: "É evidente que o efeito é ampliado pela luz elétrica, mas ela é aplicada com tanta habilidade que não se percebe sua presença [a presença, dos instrumentos]". ${ }^{101}$ (PENNELL, J.; PENNELL, E., p. 310, tradução nossa)

Por outro lado, um dos mais importantes antagonistas do realismo, Gordon Craig (1872-1966), ${ }^{102}$ tendo trabalhado como ator na companhia do Lyceum Theatre, sob a direção do seu padrasto (o próprio Irving), escreveu um livro cujo título é Henry Irving (1930), no qual revela que dele herdou sua vocação para o claro-escuro no palco. Entre Irving e Craig, o teatro fortaleceu a proposição realista já anunciada pelo primeiro e por tantos outros, cada um com seus interesses e abordagem particular.

100 "In fact, darkness was found to be, when under control, as important a factor in light [...]." 101 "Of course the effect is heightened by the electric light, but so skillfully that you are not made aware of it." 102 Enteado de Irving - companheiro de sua mãe, a atriz Ellen Terry (1847-1928). 